\title{
APLIKASI PEMETAAN FASILITAS DAN PELAYANAN UMUM DI KABUPATEN LAMONGAN DENGAN SIG BERBASIS ANDROID
}

\author{
Tri Setyo Utomo ${ }^{1)}$, Siti Mujilawati ${ }^{2}$, Nur Qomariyah ${ }^{3)}$ \\ ${ }^{1)}$ Program Studi Teknik Informatika Universitas Islam Lamongan \\ ${ }^{2)}$ Dosen Fakultas Teknik Prodi Teknik Informatika Universitas Islam Lamongan \\ ${ }^{3)}$ Dosen Fakultas Teknik Prodi Teknik Informatika Universitas Islam Lamongan \\ E-mail : satya18@gmail.com
}

\begin{abstract}
ABSTRAK
Perkembangan yang pesat tidak hanya teknologi perangkat keras dan perangkat lunak saja, tetapi metode komputasi juga ikut berkembang. Salah satu metode komputasi yang cukup berkembang saat ini adalah penyajian informasi geografis. Kabupaten Lamongan merupakan wilayah kota yang sedang berkembang seperti pada tempat-tempat industri, pariwisata, pendidikan, sarana transportasi umum dan fasilitas. Selama ini pengetahuan tentang lokasi di wilayah Kabupaten Lamongan dilakukan dengan cara datang ke lokasi langsung sehingga memerlukan waktu yang lama. Oleh karena itu, diperlukan adanya suatu Aplikasi berbasis android yang dapat membantu memberikan informasi kepada masyarakat tentang tempat dan fasilitas umum di Kabupaten Lamongan berdasarkan data atribut dan data spasial yang mendukung. Telah dibuat aplikasi GIS berbasis android untuk pemetaan fasilitas dan pelayanan umum di Kabupaten Lamongan dengan SIG berbasis android dengan menggunakan beberapa aplikasi seperti eclipse dan adobe photoshop sebagai editing gambar SIG tujuanya mampu memberikan kemudahan-kemudahan yang diinginkan serta memudahkan dalam melihat fenomena kebumian dengan perspektif yang lebih baik.Hasil dari keseluruhan ini dapat di simpulkan program ini cukup baik ada pun kekurangannya belum lengkap.
\end{abstract}

\section{Kata Kunci :Pemetaan, Pelayanan, Android}

\section{Pendahuluan}

Perkembangan teknologi di era globalisasi saat ini berlangsung sangat cepat. Teknologi informasi sudah menjadi hal yang sangat lumrah dan sebuah keharusan dalam segala aspek kehidupan. Tak hanya itu, saat ini teknologi informasi bahkan telah menjadi tulang punggung kehidupan manusia dalam penyediaan dan pemberian informasi. Keberadaan sebuah informasi yang realtime, cepat, dan akurat menjadi hal yang sangat penting bagi kelangsungan hidup manusia saat ini. Data dan informasi yang diperlukan tentu harus mudah diakses dengan efektif dan efisien oleh berbagai pihak yang berkepentingan.

Selama ini pengetahuan tentang lokasi di wilayah Kabupaten Lamongan dilakukan dengan cara datang ke lokasi langsung sehingga memerlukan waktu yang lama. Oleh karena itu, diperlukan adanya suatu tools berbasis android yang dapat membantu memberikan informasi kepada masyarakat tentang tempat dan fasilitas umum di
Kabupaten Lamongan berdasarkan data atribut dan data spasial yang mendukung. Sistem informasi geografis merupakan alat bantu untuk menyampaikan informasi mengenai pemetaan tempat fasilitas dan pelayanan umum di Kabupaten Lamongan. Dalam pencarian lokasi tentu membutuhkan letak atau suatu posisi yang dikenal sebagai informasi geografis. Informasi geografis yang paling banyak digunakan masyarakat pada saat ini yaitu aplikasi Google Maps. Dengan adanya sistem informasi geografis berbasis android tersebut akan memberikan alternatif kemudahan kepada masyarakat untuk mencari informasi mengenai tempat fasilitas dan pelayanan umum di Kabupaten Lamongan serta merupakan salah satu langkah atau cara untuk memfasilitasi masyarakat agar mudah mengenal Budaya, Pemerintahan dan Wisata di Kabupaten Lamongan.

Berdasarkan latar belakang di atas, maka dibuat judul "APLIKASI PEMETAAN FASILITAS DAN PELAYANAjN UMUM 


\section{KABUPATEN LAMONGAN DENGAN SIG BERBASIS ANDROID".}

Adapun tujuan dari penelitian ini adalah sebagai berikut :

Membangun aplikasi pemetaan fasilitas dan pelayanan umum di kabupaten Lamongan dengan SIG berbasis android dan Menentukan akurasi aplikasi pemetaan fasilitas dan pelayanan umum di kabupaten Lamongan dengan SIG berbasis android

Adapun tujuan dari penelitian ini adalah sebagai berikut : Menambah wawasan dan pengetahuan terhadap sebuah aplikasi untuk membangun sistem informasi geografis yang kompleks terutama berbasis android Bagi pengguna dari hasil pembutan game ini diharapkan dapat memberikan motivasi.

\section{TINJUAN PUSTAKA}

\section{Konsep Dasar Sistem}

Dalam perancangan suatu sistem informasi diarahkan kepada pemanfaatan teknologi secara maksimal yang terdiri dari beberapa elemen atau komponen yang membentuk jaringan kerja dan mempunyai tujuan yang ingin dicapai.

Suatu sistem dapat terdiri dari sistem bagian (subsistems). Sebagai misal, sistem komputer dapat terdiri dari subsistem yang lebih kecil lagi atau terdiri dari komponenkomponen. Subsistem perangkat keras (hardware) dapat terdiri dari alat masukkan, alat pemroses, alat keluaran dan simpanan luar. Subsistem- subsistem saling berinteraksi dan saling berhubungan membentuk satu kesatuan hingga tujuan/sasaran sistem tersebut dapat tercapai. Interaksi dari subsistem- subsistem sedemikian rupa, sehingga dicapai suatu kesatuan yang terpadu atau terintegrasi (integrated).

\section{Definisi Sistem Informasi Geografis}

Menurut Prahasta (2009), "sistem informasi geografis adalah gabungan dari tiga unsur pokok yaitu sistem, informasi dan geografis. Dengan memperhatikan pengertian sistem informasi, maka sistem informasi geografis merupakan suatu kesatuan formal yang terdiri dari berbagai sumber daya fisik dan logika yang berkenaan dengan objek-objek yang terdapat di permukaan bumi. SIG juga merupakan sejenis perangkat lunak yang dapat digunakan untuk pemasukan, penyimpanan, manipulasi, menampilkan dan keluaran informasi geografis berikut atribut-atributnya".
Menurut Burrough (2009), "sistem informasi geografis adalah sekumpulan alat untuk mengumpulkan, menyimpan, mengambil kembali saat dibutuhkan, menstransformasikan dan menampilkan suatu data spasial dari dunia nyata untuk suatu kebutuhan tertentu".

\section{Peta}

Peta merupakan gambaran wilayah geografis, bagian permukaan bumi yang disajikan dalam berbagai cara yang berbeda, mulai dari peta konvensional yang tercetak hingga peta digital yang tampil di layar komputer. Peta dapat digambarkan dengan berbagai gaya, masing-masing menunjukkan permukaan yang berbeda untuk subjek yang sama untuk menvisualisasikan dunia dengan mudah, informatif dan fungsional.

Peta berbasis komputer (digital) lebih serba guna dan dinamis karena bias menunjukkan banyak view yang berbeda dengan subjek yang sama. Peta ini juga memungkinkan perubahan skala, animasi gabungan, gambar, suara, dan bisa terhubung ke sumber informasi tambahan melalui internet. Peta digital dapat diupdate ke peta tematik baru dan bisa menambahkan detail informasi geografi lainnya. (Carter \& Agtrisari, 2003)

\section{Google Maps}

Google Maps adalah sebuah jasa peta globe virtual gratis dan online disediakan oleh Google dapat ditemukan di http://maps.google.com (Wikipedia.org). Ia menawarkan peta yang dapat diseret dan gambar satelit untuk seluruh dunia dan barubaru ini, Bulan, dan juga menawarkan perencana rute dan pencari letak bisnis di U.S., Kanada, Jepang, Hong Kong, Cina, UK, Irlandia (hanya pusat kota) dan beberapa bagian Eropa.

\section{Pengertian Java}

Menurut Raharjo, Heryanto, haryono (Mudah Belajar Java 2010) java adalah bahasa pemrograman yang dapat dijalankan di berbagai komputer termasuk telepon genggam. Bahasa ini awalnya dibuat oleh James Gosling saat masih bergabung di Sun Microsistems saat ini merupakan bagian dari Oracle dan dirilis tahun 1995. Bahasa ini banyak mengadopsi sintaksis yang terdapat pada $\mathrm{C}$ dan $\mathrm{C}++$ namun dengan sintaksis model objek yang lebih sederhana serta dukungan rutin-rutin aras 
bawah yang minimal. Aplikasi-aplikasi berbasis Java umumnya dikompilasi ke dalam p-code (bytecode) dan dapat dijalankan pada berbagai Mesin Virtual Java (JVM). Java merupakan bahasa pemrograman yang bersifat umum/non-spesifik (general purpose), dan secara khusus didisain untuk memanfaatkan dependensi implementasi seminimal mungkin. Karena fungsionalitasnya yang memungkinkan aplikasi Java mampu berjalan di beberapa platformsistem operasi yang berbeda, Java dikenal pula dengan slogannya, "Tulis sekali, jalankan di mana pun". Saat ini Java merupakan bahasa pemrograman yang paling populer digunakan, dan secara luas dimanfaatkan dalam pengembangan berbagai jenis perangkat lunak aplikasi ataupun aplikasi berbasis web.

\section{Pengertian Eclip}

Menurut Safaat (Pemrograman aplikasi mobeli smartphone dan tablet PC berbasis android 2012:16) Eclipse adalah sebuah IDE (Integrated Development Environment) untuk mengembangkan perangkat lunak dan dapat dijalankan di semua platform (platformindependent). Berikut ini adalah sifat dari Eclipse :

a. Multi-platform: Target sistem operasi Eclipse adalah Microsoft Windows, Linux, Solaris, AIX, HP-UX dan Mac OS $X$.

b. Mulit-language: Eclipse dikembangkan dengan bahasa pemrograman Java, akan tetapi Eclipse mendukung pengembangan aplikasi berbasis bahasa pemrograman lainnya, seperti $\mathrm{C} / \mathrm{C}++$, Cobol, Python, Perl, PHP, dan lain sebagainya.

c. Multi-role: Selain sebagai IDE untuk pengembangan aplikasi, Eclipse pun bisa digunakan untuk aktivitas dalam siklus pengembangan perangkat lunak, seperti dokumentasi, test perangkat lunak, pengembangan web, dan lain sebagainya.

Eclipse pada saat ini merupakan salah satu IDE favorit dikarenakan gratis dan open source, yang berarti setiap orang boleh melihat kode pemrograman perangkat lunak ini. Selain itu, kelebihan dari Eclipse yang membuatnya populer adalah kemampuannya untuk dapat dikembangkan oleh pengguna dengan komponen yang dinamakan plug-in. Eclipse dibuat dari kerja sama antara perusahaanperusahaan anggota 'Eclipse Foundation' (beserta individu-individu lain). Banyak nama besar yang ikut dalam 'Eclipse Foundation', termasuk IBM, BEA, Intel, Nokia, Borland. Eclipse bersaing langsung dengan Netbeans IDE.

\section{Gambaran Umum Obyek Penelitian}

Kabupaten Lamongan memiliki luas wilayah kurang lebih $1.812,80 \mathrm{Km}^{2}$ setara $181.280 \mathrm{Ha}$ atau $\pm 3.78 \%$ dari luas wilayah Propinsi Jawa Timur dengan panjang garis pantai sepanjang $47 \mathrm{Km}$. Batas wilayah administratif Kabupaten Lamongan adalah :

a. Sebelah Utara : Berbatasan dengan Laut Jawa

b. Sebelah Timur : Berbatasan dengan Kabupaten Gresik

c. Sebelah Selatan : Berbatasan dengan Kab. Jombang dan Kab. Mojokerto

d. Sebelah Barat : Berbatasan dengan Kab. Bojonegoro dan Kab. Tuban.

Kabupaten Lamongan memiliki banyak potensi pariwisata yang tersebar di beberapa wilayah kecamatan, objek wisata di Kabupaten Lamongan terdiri dari Wisata Alam (Wisata Bahari Lamongan, Waduk Gondang,Goa Maharani dan Zoo dan Sumber mata air Panas Tepanas), Wisata Budaya (Monumen van Der Wijck, Makam Sunan Drajad, Makam Sendang Duwur, Makam Joko Tingkir, Makam Nyai Ratu Andongsari dan Desa Balun). dan Wisata Buatan (TPI di Wilayah Pantura dan Sudetan Bengawan Solo). Selain itu juga terdapat Pusat Promosi dan Penjualan Produk Unggulan Kabupaten Lamongan, Produk Industri Kerajinan dan Makanan Khas.

\section{PEMBAHASAN}

\section{Kebutuhan Informasi}

Output yang dihasilkan oleh sistem di implementasikan berupa data spasial pada peta di google maps terdiri dari:

1. Digunakan untuk menginformasikan lokasi fasilitas umum dan pelayanan di Kabupaten Lamongan lengkap dengan fasilitas pendukung.

2. Digunakan untuk menampilkan peta lokasi fasilitas umum dan pelayanan di Kabupaten Lamongan dan fasilitas pendukungnya yang di lengkapi dengan peta. 


\section{Perancangan Basis Data}

Menguraikan perancangan media penyimpanan data dalam aplikasi dengan menggunakan metode ER-D Model dan teknik normalisasi untuk menghasilkan tabel-tabel dalam basis data. Serta dilengkapi dengan kamus data. Desain database digunakan untuk merancang sebuah database yang akan digunakan pada sistem.

\section{Use Case Diagram}

Pada gambar ini akan dijelaskan tentang Use Case Diagram pada system aplikasi :

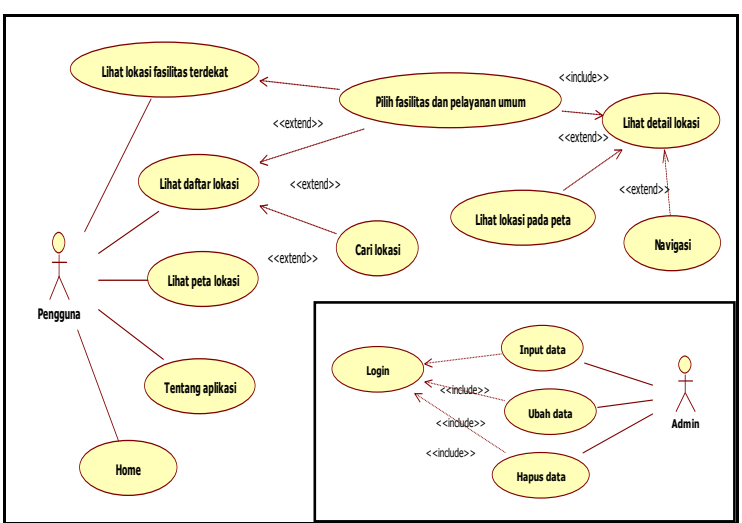

Gambar 1 Use Case Diagram

\section{Activity Diagram}

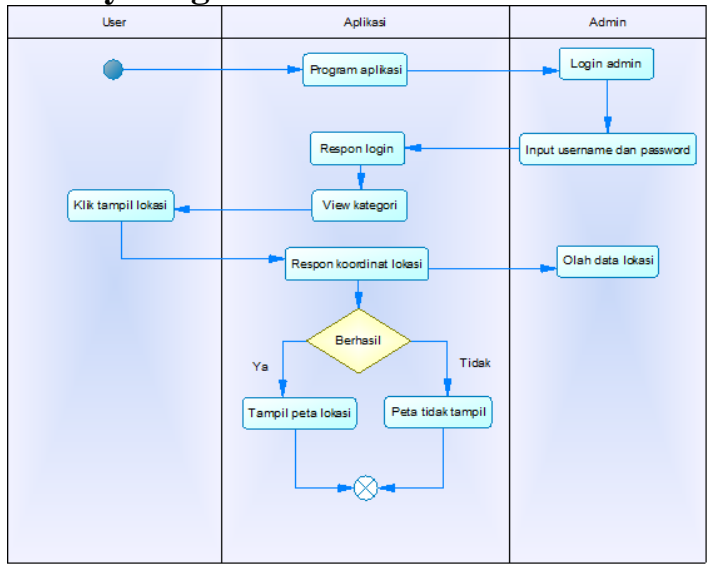

Gambar 2 Activity Diagram

Sequence Diagram

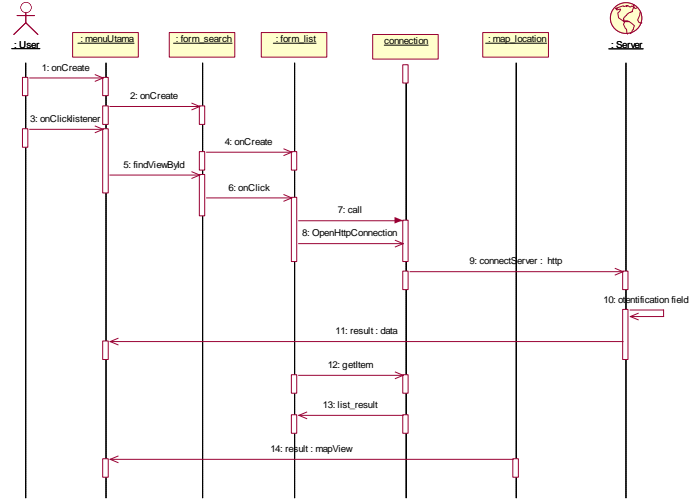

Gambar 3 Sequence Diagram

Perancangan Antarmuka/Interface

Rancangan masukan bertujuan untuk memenuhi kebutuhan pemakai dalam berinteraksi dengan sistem yang telah dibuat. Rancangan ini sangat penting dalam sistem pengolahan data, adapun input data yang dimasukkan ke dalam sistem harus dipersiapkan dengan baik agar output yang dihasilkan sesuai dengan yang diharapkan

\section{Uji Coba Pendukung}

- Menu Utama

Menu utama ini adalah menu yang pertama kali muncul untuk masuk pada aplikasi.

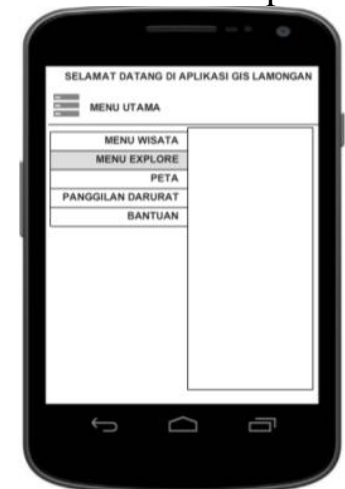

\section{Gambar 4 Menu Utama}

- Menu Mulai Explore Android

Menu explore Android yang berisikan menu intansi, hotel, kuliner, rumah sakit dan transportasi. 


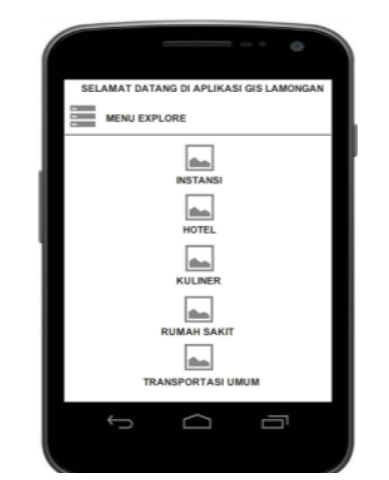

Gambar 5 Menu Explore

- Menu Navigasi

Menu navigasi ini merupakan halaman digunakan untuk menampilkan ret atau jarak atau rute lokasi

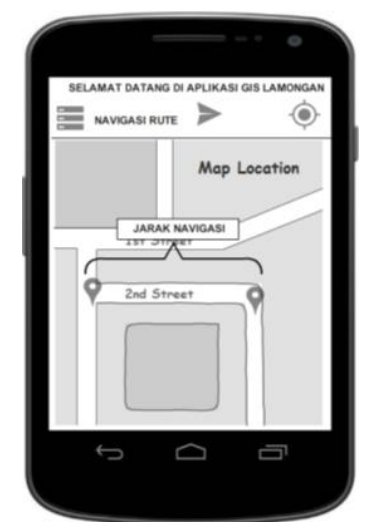

Gambar 6 Menu Navigasi

Halaman App Drawer Menu Utama

Halaman ini digunakan untuk menampilkan menu-menu untuk dapat mengakses aplikasi gis pemetaan fasilitas dan pelayanan umum di Kabupaten Lamongan ini. Berikut tampilan halaman app drawer menu utama :

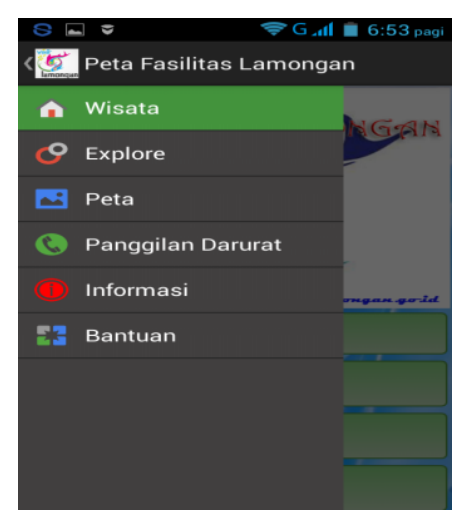

\section{Gambar 7 Tampilan Menu App Drawer}

\section{Halaman Tampil Peta Lokasi}

Halaman ini digunakan untuk menampilkan peta lokasi sesuai latitude dan longitude. Berikut tampilan halaman peta lokasi;

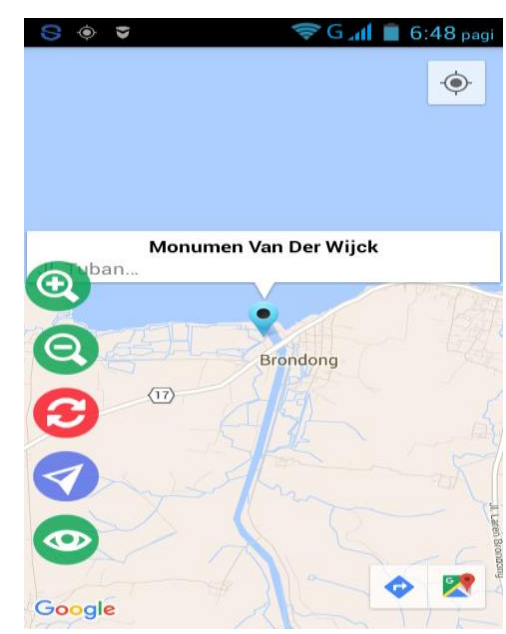

\section{Gambar 8 Tampilan Halaman Peta Lokasi}

\section{Halaman Imput Data Lokasi Wisata}

Form ini digunakan untuk menginput data-data lokasi wisata beserta informasi yang berkaitan. Berikut tampilan halaman input data wisata :

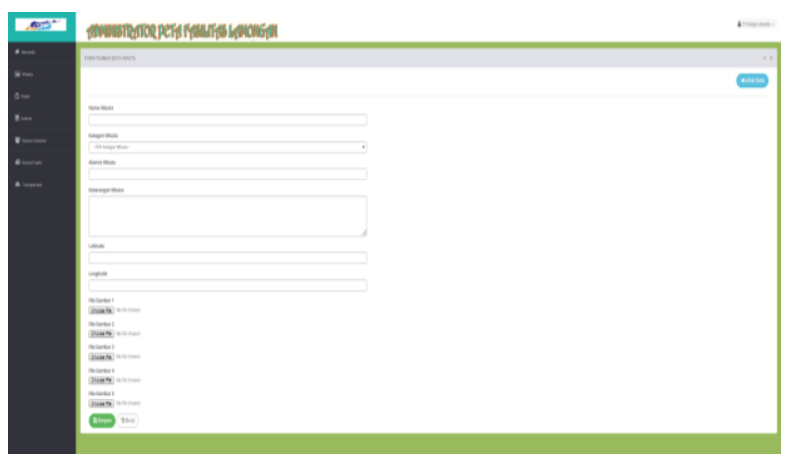

\section{Gambar 9 Tampilan Halaman Input Data} Lokasi Wisata

\section{Kesimpulan}

Berdasarkan hasil penelitian yang dilakukan oleh penulis, serta penjelasan dan analisa dari uraian bab-bab sebelumnya, maka dapat disimpulkan bahwa:

1. Telah dibuat aplikasi GIS berbasis android dengan menggunakan beberapa aplikasi seperti eclipse dan adobe photoshop sebagai editing gambar.

2. Dari hasil pengujian aplikasi diperoleh 98\% ketepatan akurasi tentang lokasi dan informasi fasilitas pelayanan umum di kab. Lamongan.

\section{Saran}

Setelah mengembangkan sistem pendukung keputusan ini, ada beberapa saran yang harus diterapkan guna pengembangan sistem 
informasi geografis pemetaan fasilitas dan pelayanan umum Kabupaten Lamongan berbasis android lebih lanjut :

Sistem informasi geografis pemetaan fasilitas dan pelayanan umum Kabupaten Lamongan berbasis android ini masih banyak terdapat kekurangan, terutama dalam proses pemetaan yang kurang spesifik. Sehingga dalam proses pemetaan sistem ini masih banyak mengalami kesalahan pengolahan datanya. Penulis menyarankan agar sistem ini dapat dikembangkan lagi agar dapat menjadi sistem yang layak digunakan dalam pemberian keputusan yang valid.

Kiranya pengembangan program aplikasi sistem informasi geografis pemetaan fasilitas dan pelayanan umum Kabupaten Lamongan berbasis android in dapat dijadikan media yang tepat bagi penggunanya, dalam menerima informasi yang akurat, terpercaya dan memiliki nilai yang efektif serta efisien bagi pengguna.

\section{DAFTAR PUSTAKA}

Burrough, Sistim Informasi Ggeografis, 2009, diakses

http://newijayanto.blogspot.co.id/2014

/02/pengertian-sistem-informasi geografis.html

Cholid Narbuko, Abu Achmadi, 2002, Metodologi Penelitian, Penerbit PT Bumi Aksara, Jakarta.

Charter, Denny dan Irma Agtrisari. 2003. Desain dan Aplikasi GIS Geographics Information System, Elex Media Komputindo : Jakarta.

Darmayuda, Ketut, 2007, Pemrograman Aplikasi Client Server. Penerbit Informatika, Bandung.

Hutabarat, Bernaridho I, 2004, Pengelolaan Basis Data, Penerbit Andi, Yogyakarta.

Hartono, Pengolahan Data, 2006, diakses http://aaudien.blogspot.co.id/2012/01/pengertia n-pengolahan-data.html

James A. O'brien, 2005, Pengantar SI: Perspektif Bisnis dan Manajerial (Introduction to Information Systems). PT Salemba Empat (Empan Patria), Jakarta.

Jeffery L. Whitten, Lonnie D. Bentley, Kevin C. Dittman, 2004, Metode Desain dan
Analisis Sistem, Penerbit Andi, Yogyakarta.

Jogiyanto, HM, 2005, Analisis dan Desain Sistem Informasi : Pendekatan terstruktur teori dan praktek aplikasi bisnis, Penerbit Andi, Yogyakarta.

Kusrini, Pengertian Sistem Informasi, 2007, diakses.http://h4cking.blogspot.co.id/2 013/12/pengertian-sistem-informasi sistem.html

Nugroho, Bunafit, 2010, Membuat Website Sendiri dengan PHP-MySQL, Penerbit Mediakita, Yogyakarta.

Prahasta. 2009. Sistim Informasi Goegrafis konsep-konsep dasar. Informatika: Bandung.

Pressman, Metode pengembangan sistem sekuensial linier, 2003, diakses. http://evafinufa25.blogspot.com/2013/ 04/rpl-tentang-model-waterfall.html

Safaat, 2012. Pemrograman Aplikasi Mobile Smartphone dan Tablet PC berbasis android, Cetakan Pertama, Edisi Revisi, Penerbit Informatika Bandung.Bandung

Nugroho. 2009. Rekayasa Perangkat Lunak Menggunakan UML \& Java. Diakses http://ki.bnlib.web.id//index.php? 